\title{
Surgical treatment of colorectal liver metastases - a single center experience over 20 years
}

\author{
Sorin Alexandrescu*, Andrei Diaconescu*, Razvan Grigorie, Zenaida lonel, Doina Hrehoreț, \\ Vladislav Braşoveanu, Mihnea Ionescu, Irinel Popescu
}

Corresponding author:

Irinel Popescu, MD, PhD, FACS,

FEBS, Professor of Surgery, Director

of "Dan Setlacec" Center of General

Surgery and Liver Transplantation,

Fundeni Clinical Institute, Bucharest,

Sos. Fundeni, no. 258, sector 2,

Romania

E-mail: irinel.popescu220@gmail.com

\author{
"Dan Setlacec" Center of General Surgery and Liver Transplantation Fundeni Clinical Institute, \\ Bucharest, Romania
}

*These authors have contributed equally to this work

\section{ABSTRACT}

Background: Increased frequency of hepatic resection and advances in oncological therapy dramatically improved the long-term outcome of the patients with colorectal liver metastases. The aim of the study is to present the short and long-term results after surgery in patients with colorectal liver metastases, in a single center, over the last two decades.

Method: Between 1995 and 2014, a curative-intent liver resection was performed in 526 patients with liver only metastases and 71 patients with both hepatic and extrahepatic metastases of colorectal origin.

Results: In patients with liver only metastases, the 1-, 3- and 5-years overall survival rates were $89 \%, 51.9 \%$ and $30 \%$, respectively. The morbidity rates were higher in synchronous liver metastases undergoing simultaneous resection. The mortality and survival rates were similar for simultaneous and staged resections $(p>0.05)$. The morbidity, mortality and survival rates for initially unresectable liver metastases rendered to resectability were similar to those of initially resectable metastases $(p>0.05)$. In patients with hepatic and extrahepatic metastases, the survival rate was significantly lower than in patients presenting liver only metastases $(p=0.001)$. Complete resection of the metastases was associated with significantly longer survivals, compared with a palliative hepatectomy $(p=0.039)$.

Conclusion: Liver resection offers the chance of more than 5 years survival to $30 \%$ of patients with colorectal cancer liver metastases.

Key words: colorectal liver metastases, simultaneous resection, initially unresectable liver metastases, extrahepatic metastases.

\section{INTRODUCTION}

Colorectal cancer (CRC) ranks three among the cancers of adults and is the third leading cause of cancer death (1). In 2013 in Romania, colorectal cancer is ranked second as prevalence (after lung cancer) and ranks two as the number of cancer-related deaths (after lung cancer) (2).

The main cause of death in patients with colorectal cancer is metastatic 
disease. The liver is the most common site of metastases (3).

About $50-65 \%$ of patients with colorectal cancer will develop liver metastases (CRLM) (4) of which 16-25\% are synchronous and $30-40 \%$ are metachronous (5-7). Other sites of CRC metastases involve peritoneum and ovary (15\%), lung (10.2\%), brain (1.7\%) and bone (1.9\%) (8).

The last 20 years experience has shown that for patients with CRLM, liver resection offers the highest survival rates, ranging between $25 \%$ and $50 \%$ at 5 years (9-12).

However, some issues related to the indication and the benefit of liver resection in peculiar situations, as well as the optimal timing of liver resection, is still a subject of debate. Simultaneous resection of the primary tumor with synchronous CRLM is still controversial. The benefit of recurrent metastases resection, although supported by several studies, is considered marginally effective by others.

In the last decade the possibility of conversion to resectability for some patients with initially unresectable CRLM became unquestionable, representing the main treatment choice for a prolonged survival in these patients. In addition, resection of the hepatic and extrahepatic metastases has become more widely used, with encouraging results.

Last but not least, the combination of liver resection with radiofrequency ablation of CRLM located in the residual liver parenchyma (future liver remnant - FLR) appears to increase patient survival, compared with those who received only palliative oncologic treatment.

In the present paper there are presented the results after liver resections for CRLM, in a large single center experience, over a period of 20 years.

\section{PATIENTS AND METHODS}

A retrospective study analyzed the prospectively introduced data of 597 patients (262 women and 335 men), aged between 24 and 84 years-old, diagnosed with CRLM, who underwent surgical treatment from January 1995 to December 2014 in the "Dan Setlacec" Center of General Surgery and Liver Transplantation from Fundeni Clinical Institute, Bucharest.

In the present cohort of patients, a total number of 670 liver resections were performed. Out of these, 73 were re-resections. The data were obtained both by studying medical records and surgical protocols from an electronic database recording patients who underwent hepatectomies for CRLM, established in our Department.
Morbidity, mortality and overall survival rates were calculated for the whole set and also for different subsets of patients (i.e., synchronous vs. metachronous CRLM, simultaneous resection vs. delayed resection, first liver resection vs. re-resection of recurrent CRLM, initially resectable CRLM vs. initially unresectable rendered to resectability, hepatic and extrahepatic metastases vs. liver only metastases).

The data are presented as number (percentage). The comparison between the groups was made using the Chi-square test. The survivals were assessed using the Kaplan-Meier curves; the log-rank test was used to compare the survivals between the groups. A p value less than 0.05 was considered statistically significant.

\section{RESULTS}

\section{LIVER ONLY COLORECTAL METASTASES}

In the 526 patients diagnosed with liver only colorectal metastases, 595 liver resections (69 iterative resections) were performed. Among the 60 patients who underwent liver re-resections, 52 patients had a single iterative resection, 7 patients had 2 iterative resections and 1 patient had three iterative resections.

The morbidity rate was $33.07 \%(174 / 526)$ and the mortality rate was $2.85 \%(15 / 526)$. In patients with liver only CRLM, the median survival time was 37.8 months and the $1-, 3$ - and 5 -years survival rates were $89 \%$, $51.9 \%$ and $30 \%$, respectively (figure 1 ).

Out of the 526 patients with liver only CRLM, 492 patients had initially resectable CRLM and 34 patients had initially unresectable CRLM rendered to resectability.

\section{Initially resectable CRLM}

In patients with initially resectable CRLM, the morbidity rate was $32.72 \%(161 / 492)$ and the mortality rate was $2.84 \%(14 / 492)$.

The 1-, 3- and 5-years survival rates were $89.1 \%$, $54.7 \%$ and $31.2 \%$, respectively. The median survival time was 38.7 months (figure 2).

Out of the 492 patients with initially resectable CRLM, 272 had synchronous and 220 metachronous CRLM.

\section{Synchronous CRLM}

In patients with synchronous CRLM, the mortality rate was $4.04 \%$ (11/272). The overall morbidity rate was $39.33 \%$ (107/272) and the median survival time was 39.6 months.

The 1-, 3- and 5-years survival rates were: $88.6 \%$, 
Figure 1 - Comparative overall survival between patients with liver only metastases and patients with hepatic and extrahepatic metastases
Figure 2 - Comparative overall survival between initially resectable patients and patients with initially unresectable CRLM rendered to resectability
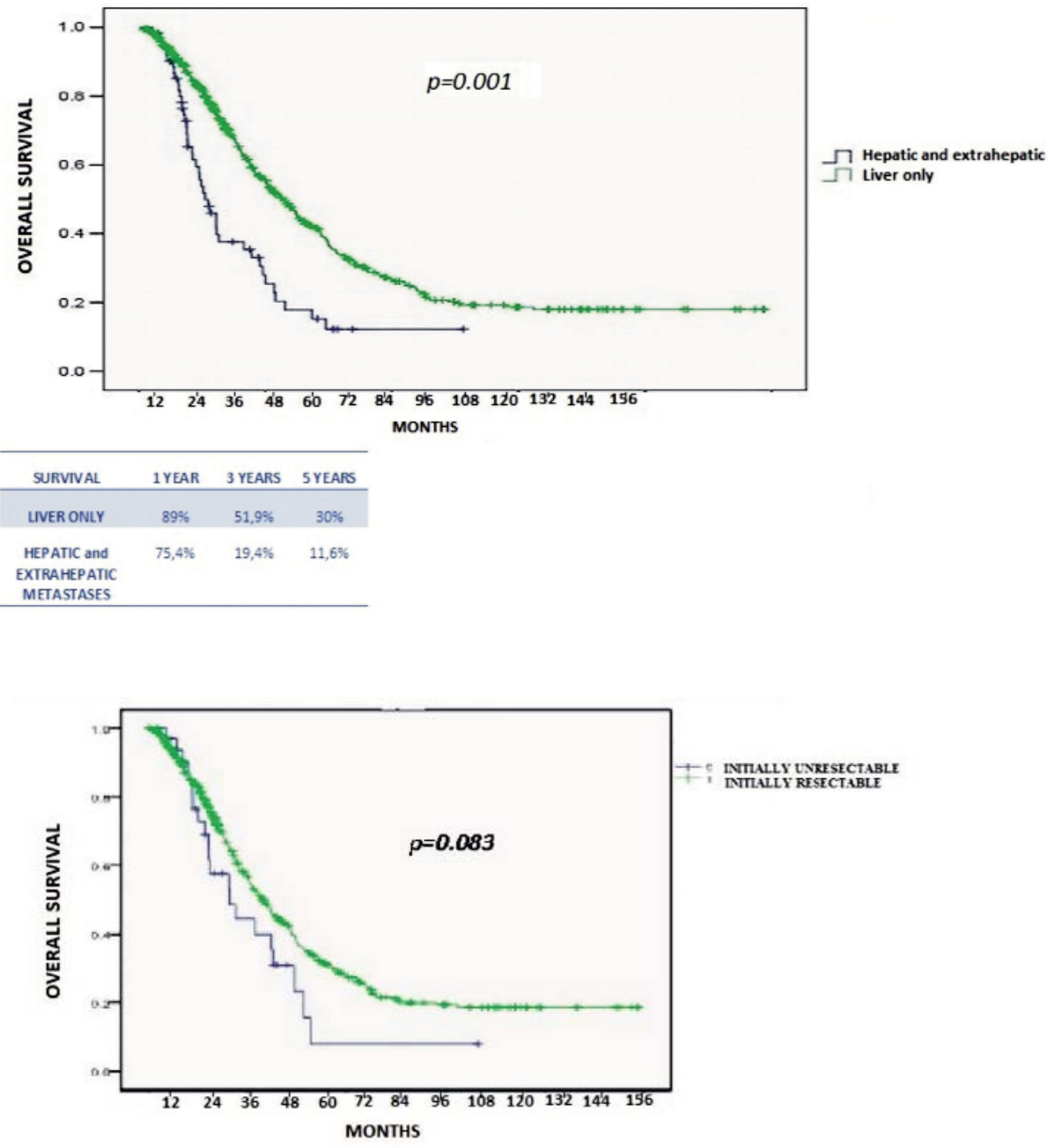

\begin{tabular}{lccl}
\hline \multicolumn{1}{c}{ SURVIVAL } & $\begin{array}{c}1 \\
\text { year }\end{array}$ & $\begin{array}{l}3 \\
\text { years }\end{array}$ & $\begin{array}{l}5 \\
\text { years }\end{array}$ \\
\hline $\begin{array}{l}\text { Initially } \\
\text { resectable }\end{array}$ & $86.4^{3} \%$ & $54.8 \%$ & $35.3 \%$ \\
$\begin{array}{l}\text { Initially } \\
\text { unresectable }\end{array}$ & $90.4 \%$ & $39.9 \%$ & $7.8 \%$ \\
\hline
\end{tabular}

$50.6 \%$ and $30.8 \%$, respectively (figure 3 ).

The 272 patients with "liver only" synchronous initially resectable CRLM underwent either simultaneous resections (214 patients) or staged resection (54 patients underwent initial resection of the primary tumor and then the metastasis resection - "delayed liver resection", and in 4 patients was performed initial resection of the CRLM and subsequent resection of the primary tumor - „liver first approach").

\section{Simultaneous resection}

The mortality rate was $4.2 \%(9 / 214)$, the morbidity rate was $42.9 \%$ (92/214) and the median survival time was 38.7 months. The 1-, 3- and 5-years survival rates were $88.7 \%, 52 \%$ and $31.1 \%$, respectively (figure 4).
Out of the 214 patiens with simultaneous resection, 17 were treated by minimally invasive approach of the primary tumor (7 patients - robotic approach and 10 patients laparoscopic approach). In these 17 patients, liver resection was performed either through a right subcostal incision (13 patients), or by laparoscopic approach (4 patients).

\section{Delayed liver resection}

The mortality rate was $3.7 \%(2 / 54)$, the morbidity rate was $22.22 \%(12 / 54)$ and the median survival time was 37.8 months. The 1-, 3- and 5-years survival rates were $88.1 \%, 52.7 \%$ and $22.3 \%$, respectively, similar to those achieved in patients with simultaneous resection $(p=0.314)$ (figure 4). 
Figure 3 - Comparative overall survival between patients with synchronous and metachronous colorectal liver metastases
Figure 4 - Comparative overall survival between simultaneous resection group and delayed resection group

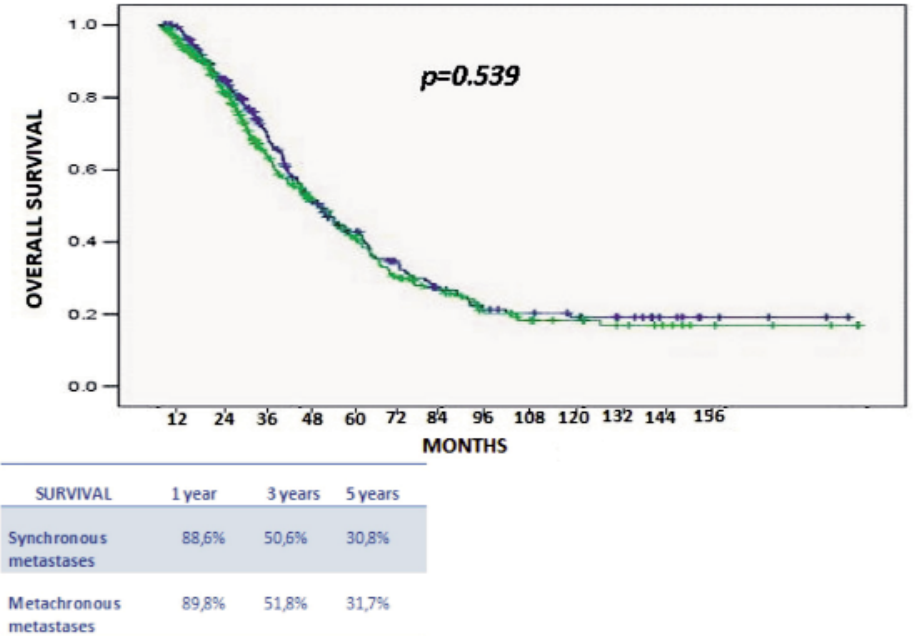

I METACHRONOUS

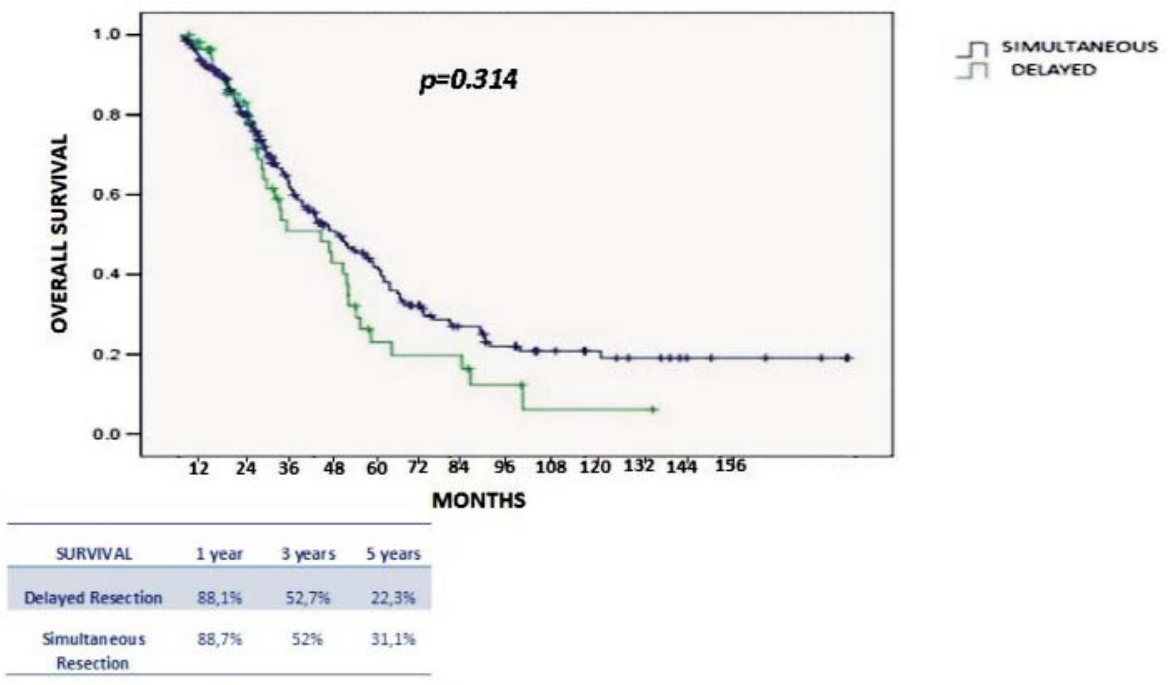

The morbidity rate in patients with simultaneous resection was significantly higher compared with patients with delayed resection ( $p=0.005)$, but with no differences regarding the mortality rates $(p=1)$

\section{Liver first approach}

The liver first approach was applied to 4 patients ( 2 with tumor of the rectum and 2 with tumor of the colon, requiring difficult major hepatectomies). The overall morbidity rate was $75 \%$ with nil mortality.

\section{Metachronous CRLM}

In patients with initially resectable metachronous CRLM, who underwent liver resection (220/492), the mortality rate was $1.36 \%(3 / 220)$, the morbidity rate was $24.54 \%$ (54/220) and the median survival time was 37.8 months.
The 1-, 3- and 5-years overall survival rates were $89.8 \%, 51.8 \%$ and $31.7 \%$, respectively (figure 3 ).

The survival rates after hepatectomy in patients with synchronous and metachronous CRLM were simi$\operatorname{lar}(p=0.539)$.

The morbidity rate was significantly lower in patients undergoing liver resection for metachronous metastases compared with patients with synchronous metastases $(p=0.001)$. No differences of the mortality rates were observed between the groups $(p=0.084)$.

The morbidity rate of patients with liver resection for metachronous metastases was similar to those recorded in patients with synchronous CRLM undergoing delayed liver resection $(p=0.255)$. The mortality rates were also similar among these two groups $(p=0.859)$. 


\section{Initially unresectable CRLM}

In 34 patients with initially unresectable CRLM the conversion to resectability was achieved.

Portal vein ligation/embolisation (PVL/PVE) was performed in 18 patients in order to render to resectability initially unresectable liver metastases, but only 10 patients underwent further hepatectomy.

The morbidity and mortality rates after hepatectomy in this group of patients were $38.23 \%(13 / 34)$ and $2.94 \%(1 / 34)$, respectively. These results are not significantly different compared to those observed in patients with initially resectable CRLM ( $p=0.5724$ for the morbidity rates and $p=1$ for the mortality rates).

The 1-, 3- and 5-years survival rates were $90.4 \%$, $39.9 \%$ and $7.8 \%$, respectively. The median survival time was 27.2 months (figure 2), similar to those achieved in patients with initially resectable metastases $(p=0.083)$.

\section{HEPATIC AND EXTRAHEPATIC CRLM}

In 71 patients undergoing liver resection for CRLM there were present concomitant extrahepatic metastases. In these patients there were performed 75 liver resections (4 re-resections).

The morbidity rate was $35.2 \%(25 / 71)$ and the mortality rate was $5.63 \%(4 / 71)$.

Comparing the morbidity and mortality rates in patients with liver only metastases and hepatic and extrahepatic metastases, respectively, no differences were observed between the groups $(p=0.788$ and $p=0.266$, respectively).

In patients with hepatic and extrahepatic colorectal metastases, the median survival time was 18.2 months and the 1-, 3- and 5-years survival rates were $75.4 \%$, $19.4 \%$ and $11.6 \%$, respectively (figure 1 ), significantly lower compared with patients with liver only CRLM $(p=0.001)$.

Out of these 71 patients with hepatic and extrahepatic metastases, 62 underwent complete resection of the metastatic burden, while 9 patients underwent macroscopic residual (i.e., R2) resections.

The 1-, 3- and 5-years survival rates in patients with hepatic and extrahepatic metastases with a complete resection were $76 \%, 23 \%$ and $14 \%$, significantly higher compared with patients with an R2 resection: $50 \%, 13 \%$ and $0 \%(p=0.039)$ (figure 5).

\section{LIVER RE-RESECTIONS FOR RECURRENT CRLM}

Out of 597 patients whith liver resections for CRLM, 64 patients underwent re-resections for recurrent CRLM.

In liver only CRLM group, 60 patients underwent 69 liver re-resections (52 patients had a single iterative resection, 7 patients had 2 iterative resections and 1 patient had three iterative resections).

In hepatic and extrahepatic metastases group, 4 patients underwent one liver re-resection, each.

Following the second hepatectomy, the morbidity
Figure 5 - Comparative overall survival between patients with hepatic and extrahepatic metastases undergoing either $\mathrm{R} 0$ resection, or $\mathbf{R} 2$ resection

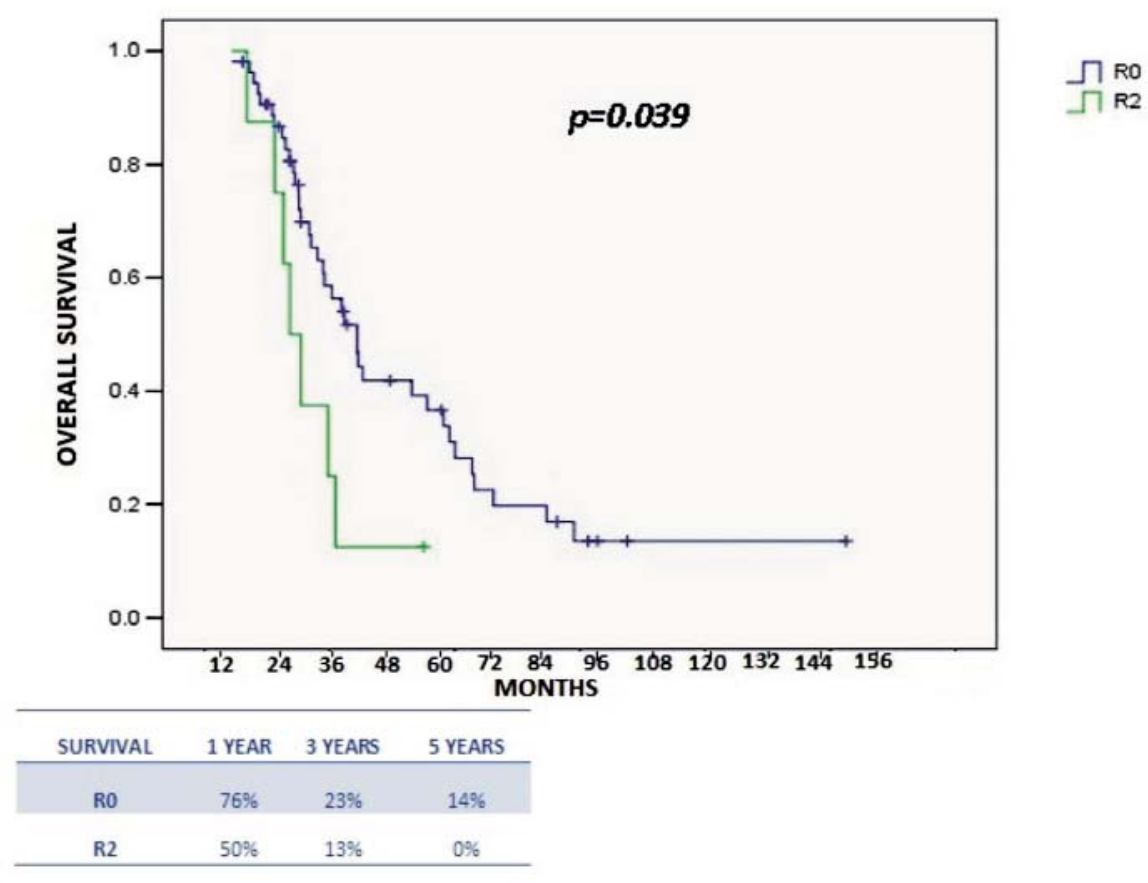


rate was $45.31 \%(29 / 64)$ and the mortality rate was $6.2 \%(4 / 64)$. Compared with the short-term results after the first liver resection, the morbidity rate after the second hepatectomy was significantly higher $(p=0.035)$, with no differences of the mortality rates $(p=0.135)$.

The 1-, 3-, and 5-years survival rates of the patients with liver re-resections for recurrent CRLM (calculated from the time of the first resection) were $98.3 \%, 67.7 \%$ and $27.6 \%$, respectively. These survival rates appears to be higher compared with those achieved in patients with a single liver resection, albeit the statistical significance was not reached ( $p=0.308$ ) (figure 6).

\section{DISCUSSIONS}

Liver metastases are the primary cause of death in patients with colorectal cancer. The management of these patients implies a multimodal treatment, which involves collaboration between surgeon, oncologist, chemotherapist, radiologist, pathologist, gastroenterologist and radiotherapist (13). Currently available therapeutic methods, in the treatment of these patients, are liver resection, ablative therapies, chemotherapeutic agents (5-FU, Oxaliplatin, Irinotecan), monoclonal antibodies (Bevacizumab, Cetuximab, Panitumumab), radioembolization (Yttrium microspheres) and chemoembolization with microspheres loaded with Irinotecan (DEBIRI - drug eluting beads Irinotecan).

The data collected retrospectively in the last 2 decades have highlighted the fact that liver resection offers the highest rates of survival, and represents the only treatment that can offer the chance of curability for some of these patients (14). The data published in December 2014 in LiverMetSurvey (an international database that included patients with CRLM operated in 302 centers from 69 countries), based on the results reported for more than 23400 patients operated for CRLM, showed that the survival rates achieved by hepatic resection is significantly higher $(p<0.01)$ compared with any other therapy (12). It was also revealed that the association between hepatic resection and ablative therapy (for patients who could not benefit from an R0 resection) offered 1-, 3- and 5-years survival rates of $84 \%, 34 \%$ and $21 \%$, respectively, significantly higher $(p<0.01)$ compared with patients with only a palliative oncologic treatment. Moreover, a study evaluating the conditions associated with prolonged survival in patients with metastatic colorectal cancer showed that the only factors that were independently correlated with an increased survival were increasing frequency of liver resections and advances in chemotherapy (15).

The survival rates in the present cohort of patients were similar to those reported in other high-volume centers $(16,17)$. For a growing number of patients with CRLM to benefit from the favorable results of liver resection, their indications were expanded in the past decade. Accordingly, the number and size of metastases,
Figure 6 - Comparative overall survival between patients undergoing only one liver resection and at least one reresection (calculated from the time of the first hepatectomy)

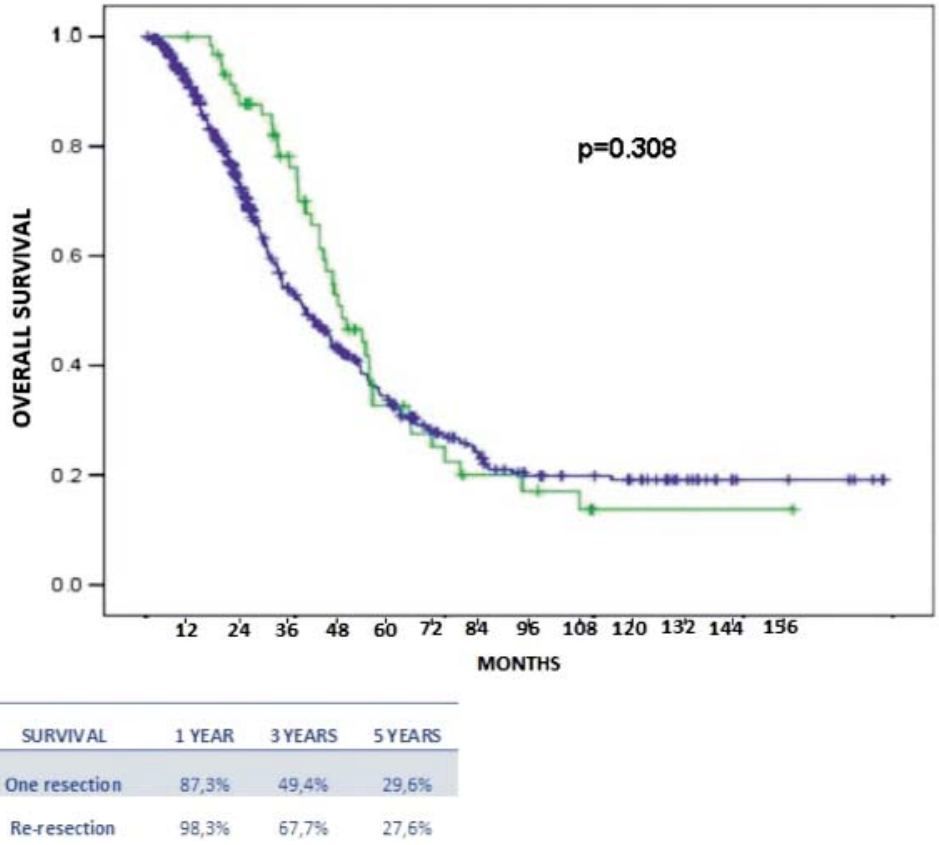

$\Pi$ One resection

Re-resected 
their bilateral location and the age of the patient are no longer contraindications of liver resection $(18,19)$.

Currently, it is considered that CRLM are resectable (20) when a complete resection can be performed (RO) $(21,22)$, at least two adjacent liver segments can be preserved with an adequate vascular inflow, outflow and bile drainage, and when the volume of the remnant liver exceeds $25-30 \%$ of the total liver volume (23-31).

Unfortunately, despite the extension of the frontiers of liver resection, the percentage of patients presenting with resectable CRLM at the moment of the diagnosis does not exceed $25 \%$ (32). To give the chance of a potentially curative resection to some patients with initially unresectable CRLM, in the last years few oncosurgical strategies have been introduced with the aim to allow conversion to resectability of these lesions (13,33-37).

In 2014 ESMO (European Society For Medical Oncology) classified unresectable CRLM into 3 groups: in the first two categories (groups 1 and 2) were included patients who potentially could be rendered to resectability, while the third group included patients with definitely unresectable metastases.

The onco-surgical strategies aiming conversion to resectability address to the groups 1 and 2 patients and include:

a) Hepatectomy after portal vein ligation/embolization (PVL/PVE) is a strategy recommended in patients without metastases in the residual liver, but whose future liver remnant (FLR) is below $30 \%$ of the total liver volume (TLV) (33). In our experience, by applying this technique, the resectability rate was $55.5 \%$ (10/18 patients), similar results being reported by other authors who employed this strategy $(30,38,39)$.

To achieve a more important hypertrophy of the FLR in a shorter period of time, the ALPPS procedure (Associating portal vein ligation and liver partition for staged liver resection) was used in the last 5 years. It leads to higher rates of resectability than PVL/PVE (85$95 \%$ ), but it is associated with increased rates of major morbidity (about 40\%) and mortality (more than 10\%) (40-43). Therefore, in present, it is considered that the indications of ALPPS are not fully established, yet, and the best way to perform this approach (up-front or after insufficient hypertrophy of the FLR following PVE, with or without transection of the right bile duct during the first procedure) has to be decided in the future.

b) "Two-stage" hepatectomy is indicated in patients with bilobar CRLM, presenting few metastases larger than $3 \mathrm{~cm}$ in the remnant liver, whose resection does not allow preservation of a sufficient FLR. Frequently, the first-stage liver resection is associated with right $\mathrm{PVL}$ in order to increase the volume of the FLR (44). By using this procedure, in our center, the rate of conversion to resectability was $45 \%$ (5/11 patients), lower than those reported by other authors $(75-81 \%)(44,45)$. This lower rate of conversion could be explained by a more cautious attitude in performing the second resection in patients with marginally sufficient liver remnant (e.g. $20-25 \%$ of the TLV). That may explain the nil mortality rates in our experience; in contrast with up to $15 \%$ mortality rates reported by other authors (who achieved higher conversion rates) (45).

c) Hepatic resection associated with ablation of CRLM from FLR is mainly recommended for patients with bilobar metastases that cannot be completely removed due to the insufficient FLR. It consists in resection of the bulk metastatic burden and ablation of the metastases (lower than $3 \mathrm{~cm}$ in maximum diameter) located in the FLR $(37,46,47)$. The survival of such patients was significantly higher than those reported for similar patients treated by palliative oncologic therapy.

d) Hepatectomy after shrinkage of liver metastases by chemotherapy is indicated in large liver metastases whose resection does not allow preservation of an adequate FLR, enough to avoid postoperative liver failure. Since 1996, the Paul Brousse group highlighted the possibility of practicing this onco-surgical approach, emphasizing that survival results are superior to those achieved by palliative chemotherapy $(25,48,49)$. In addition, the use of monoclonal antibodies may lead to an increase rate of resectability in the initially unresectable CRLM $(50,51)$.

In the present series, there were 34 patients with initially unresectable CRLM rendered to resectability. Morbidity and mortality rates, although higher in absolute value compared with patients with initially resectable liver metastases, were not statistically significant different. Other authors have shown higher rates of mortality in patients converted to resectability by "two-stage" liver resections, considering that this is determined by the more advanced state of the disease and the poorer biologic status of these patients, which could not allow them to overcome the consequences of postoperative complications (45). Similarly, in patients rendered to resectability after chemotherapy, many authors reported higher morbidity and mortality rates after hepatectomy, explaining this by the hepato-toxic potential of preoperative chemotherapy (52-55). For this reason it is recommended to perform the liver resection as soon as the metastases become resectable, as further prolongation of chemotherapy 
may increase the risks of postoperative complications or missing metastases $(56,57)$. Regarding the survival rates achieved in patients with initially unresectable CRLM rendered to resectability by different therapeutic methods, our results are similar to those reported in the other series $(25,30,45,58-62)$.

Although it is widely accepted that the treatment of choice for initially resectable liver metastases is hepatic resection, the optimal timing of resection is still a topic of debate, especially in patients with synchronous liver metastases.

The results reported in this study (similar rates of mortality and survival achieved by simultaneous or staged resection) justify simultaneous resection of the primary tumor and liver metastases. Similar results were recently published by most authors dealing with this topic $(63,64,64-66)$, recommending simultaneous resection of the primary tumor and synchronous CRLM in patients with colon cancer and requiring minor liver resection $(64,67-69)$. Because of the higher morbidity and mortality rates reported by some authors $(69,70)$ in patients undergoing simultaneous resection of the rectal tumor and/or major hepatectomies, few strategies were developed in the last years, aiming to reduce the rate of postoperative complications and deaths. Thus, minimally invasive approach of the primary tumor and replacement of major hepatectomies by ultrasound-guided limited liver resections of liver metastases could decrease the morbidity rates in patients undergoing simultaneous resection. In the present series there were 17 patients treated by minimally invasive approach of the primary tumor ( 7 patients - robotic approach of the rectal tumor and 10 patients laparoscopic approach). In these 17 patients, liver resection was performed either through a right subcostal incision (13 patients), or by laparoscopic approach (4 patients). The morbidity rate was $23.5 \%$ $(4 / 17)$ and the mortality rate was nil. These lower morbidity rates (compared to those observed in patients undergoing simultaneous resection by open surgery), although not statistically significant $(p=0.297)$, seem to justify this approaches whenever possible. These results could be explained by the avoidance of delabrant incisions (which decreases the rate of abdominal wall postoperative complications) and the lower number of liver segments resected (which decreases the morbidity and mortality rates after liver resection) (71,72). Currently, we recommend robotic resection of rectal tumors and performing hepatectomy by right subcostal incision, using this incision also to remove the specimen of colorectal resection.
When major hepatectomies could not be replaced by minor liver resections, due to the higher rates of morbidity and mortality reported in patients undergoing simultaneous resection in such instances, a consensus conference held in 2012 recommended staged resections (67). Thus, in patients with borderline resectable synchronous CRLM should be take into account the initial removal of metastases (to avoid their progression to unresectability), postponing the resection of the primary tumor (for a later time). Similarly, in patients with tumors of the mid or low rectum requiring neoadjuvant radiotherapy it is recommended to perform initially the resection of liver metastases (especially when a major hepatectomy is needed), followed by radiotherapy and, subsequently, primary tumor resection $(73,74)$. This approach was used in 4 patients from the present series, giving them the chance to undergo a complete resection of the primary tumor and liver metastases under safe conditions (mortality 0\%). This strategy cannot be used in patients who have complications of primary tumor (obstruction /perforation), so that, in such situations it is recommended the initial resection of the primary tumor followed by subsequent hepatectomy.

The results achieved in our series are similar to those recorded in a multicenter study presented in 2013, which revealed that patients with synchronous colorectal liver metastases managed with either simultaneous or staged approach had similar perioperative and long-term outcomes (75).

Although synchronous liver metastases suggest a more aggressive disease, in our series the survival of these patients was not statistically significant lower than those achieved by liver resection in patients with metachronous liver metastases $(p=0.539)$. Similar observations were reported by other authors (76) who analyzed more than 1000 patients. However, older studies suggest that the prognosis of patients with metachronous liver metastases is significantly better than those of patients presenting synchronous CRLM $(11,46,77-79)$. The apparently better survival rates of patients undergoing hepatectomy for synchronous CRLM in the last years could be explained by the routine use of an efficient adjuvant chemotherapy, which can mitigate the potentially more aggressive behavior of synchronous metastases.

Nevertheless, it is known that more than $40 \%$ of patients who received potentially curative resection of CRLM will develop recurrent liver metastases during the first 2-3 years after surgery (80-82). Liver-only recurrence occurs in one third of these patients and liver re-resection was taking into account in order to 
improve their survival (83). In the early 2000 s several authors stated that liver re-resection brings a survival benefit similar to those of the initial liver resection (84-86). Thus, Weber et al considered that "liver reresection resets the biological clock" (87). In our series, the survival (from the moment of the first resection) of the patients who received iterative hepatectomies was higher than those achieved in patients undergoing a single hepatic resection, but the difference was not statistically significant. The results achieved in the present series are similar with those reported, in the recent years, by other authors dealing with this subject, which consider that liver re-resection is safe, but is marginally effective $(80,88,89)$.

The presence of concomitant hepatic and extrahepatic metastases represents a more advanced state of the metastatic disease (stage IVB in the 7th edition of the AJCC (American Joint Committee on Cancer) cancer staging manual). However, in the last decade, the presence of extrahepatic metastases is no longer considered an absolute contraindication to liver resection (90). Thus, in our series, the 5 -years survival rate of $11.6 \%$ achieved after liver resection in such patients seems to be higher than the survival rates reported in similar patients receiving only palliative chemotherapy. Moreover, in patients with hepatic and extrahepatic metastases who underwent complete resection of the metastatic disease (R0), the survival rate at 5 years was $14 \%$, significantly higher than the 5 -years survival of $0 \%$ observed in patients who underwent only palliative liver resection (R2) ( $p=0.039)$. Similar survival rates were reported recently by other authors $(91,92)$, which identified a few favorable prognostic factors in patients with hepatic and extrahepatic metastases: the presence of up to 5 liver metastases, extrahepatic disease located only in the lung, preoperative CEA $<10$ $\mathrm{ng} / \mathrm{ml}$ and location of the primary tumor in the left colon $(93,94)$.

\section{CONCLUSION}

The progresses in liver resection increased dramatically the survival rates of patients with CRLM. Simultaneous resection provides similar mortality and survival rates as staged resections in most of the patients with synchronous CRLM. Whenever possible, major hepatectomies should be replaced by ultrasound-guided limited liver resections, and primary tumor should be approached minimally invasive. Even in patients with initially unresectable CRLM, the prognosis is improved by an aggressive multimodal treatment aiming their conversion to resectability. The presence of extrahepatic metastases is no longer a contraindication for hepatectomy, when complete resection (RO) of the metastatic disease could be achieved. Liver re-resection is a safe approach in patients with recurrent CRLM, improving their overall survival.

\section{Acknowledgement}

"This work received financial support through the project entitled "CERO - Career profile: Romanian Researcher", grant number POSDRU/159/1.5/S/135760, co financed by the European Social Fund for Sectoral Operational Programme Human Resources Development 2007-2013".

\section{REFERENCES}

1. Jemal A, Siegel R, Xu J, Ward E. Cancer statistics, 2010. CA Cancer J Clin 2010 Sep;60(5):277-300.

2. Ferlay J, Soerjomataram I, Dikshit R, Eser S, Mathers C, Rebelo M, Parkin DM, Forman D, Bray F. Cancer incidence and mortality worldwide: sources, methods and major patterns in GLOBOCAN 2012. Int J Cancer 2015 Mar 1;136(5):E359-E386

3. Leporrier J, Maurel J, Chiche L, Bara S, Segol P, Launoy G. A populationbased study of the incidence, management and prognosis of hepatic metastases from colorectal cancer. Br J Surg 2006 Apr;93(4):465-74.

4. McLoughlin JM, Jensen EH, Malafa M. Resection of colorectal liver metastases: current perspectives. Cancer Control 2006 Jan;13(1):32-41.

5. McMillan DC, McArdle CS. Epidemiology of colorectal liver metastases. Surg Oncol 2007 Jul;16(1):3-5.

6. Bengmark S, Hafstrom L. The natural history of primary and secondary malignant tumors of the liver. I. The prognosis for patients with hepatic metastases from colonic and rectal carcinoma by laparotomy. Cancer 1969 Jan;23(1):198-202

7. Bengtsson G, Carlsson G, Hafstrom L, Jonsson PE. Natural history of patients with untreated liver metastases from colorectal cancer. Am J Surg 1981 May;141(5):586-9.

8. Capussotti L. Epidemiology and natural history. In: Capussotti L, editor. Surgical Treatment of Colorectal Liver Metastases. 2011 ed. Milan: 2011. p. 1-6.

9. Popescu I, lonescu M, Alexandrescu S, Ciurea S, Hrehoret D, Sarbu-Boeti P, Boros M, Croitoru A, Anghel R. [Surgical treatment of liver metastases from colorectal cancer]. Chirurgia (Bucur) 2006 Jan;101(1):13-24.

10. Choti MA, Sitzmann JV, Tiburi MF, Sumetchotimetha W, Rangsin R, Schulick RD, Lillemoe KD, Yeo CJ, Cameron JL. Trends in long-term survival following liver resection for hepatic colorectal metastases. Ann Surg 2002 Jun;235(6):759-66

11. Scheele J, Altendorf-Hofmann A. Resection of colorectal liver metastases. Langenbecks Arch Surg 1999 Aug;384(4):313-27.

12. LiverMetSurvey . 2014. Ref Type: Online Source

13. Popescu I, Alexandrescu S. [Hepatic metastasis of colorectal cancer--current therapeutic possibilities]. Chirurgia (Bucur) 2010 Mar;105(2):155-69.

14. Scheele J, Altendorf-Hofmann A, Stangl R, Schmidt K. [Surgical resection of colorectal liver metastases: Gold standard for solitary and radically resectable lesions] Swiss Surg 1996;Suppl 4:4-17.

15. Kopetz S, Chang GJ, Overman MJ, Eng C, Sargent DJ, Larson DW, Grothey A, Vauthey JN, Nagorney DM, McWilliams RR. Improved survival in metastatic colorectal cancer is associated with adoption of hepatic resection and improved chemotherapy. J Clin Oncol 2009 Aug 1;27(22):367783

16. Rees M, Tekkis PP, Welsh FK, O'Rourke T, John TG. Evaluation of longterm survival after hepatic resection for metastatic colorectal cancer: a multifactorial model of 929 patients. Ann Surg 2008 Jan;247(1):125-35.

17. Cummings LC, Payes JD, Cooper GS. Survival after hepatic resection in metastatic colorectal cancer: a population-based study. Cancer 2007 Feb 
15;109(4):718-26.

18. Minagawa M, Makuuchi M, Torzilli G, Takayama T, Kawasaki S, Kosuge T, Yamamoto J, Imamura $\mathrm{H}$. Extension of the frontiers of surgical indications in the treatment of liver metastases from colorectal cancer: long-term results. Ann Surg 2000 Apr;231(4):487-99.

19. Cavallari A, Vivarelli M, Bellusci R, Montalti R, De RN, Cucchetti A, De VA, De RE, Salone M, La BG. Liver metastases from colorectal cancer: present surgical approach. Hepatogastroenterology 2003 Nov;50(54):2067-71.

20. Abdalla EK, Adam R, Bilchik AJ, Jaeck D, Vauthey JN, Mahvi D. Improving resectability of hepatic colorectal metastases: expert consensus statement. Ann Surg Oncol 2006 Oct;13(10):1271-80

21. Jaeck D, Bachellier $P$, Guiguet M, Boudjema $K$, Vaillant JC, Balladur $P$, Nordlinger B. Long-term survival following resection of colorectal hepatic metastases. Association Francaise de Chirurgie. Br J Surg 1997 Jul;:84(7):977-80.

22. Jaeck D, Bachellier P, Weber JC, Boudjema K, Mustun A, Paris F, Schaal JC, Wolf $P$. [Surgical strategy in the treatment of synchronous hepatic metastases of colorectal cancers. Analysis of a series of 59 operated on patients]. Chirurgie 1999 Jun;124(3):258-63.

23. Vauthey JN, Pawlik TM, Abdalla EK, Arens JF, Nemr RA, Wei SH, Kenname DL, Ellis LM, Curley SA. Is extended hepatectomy for hepatobiliary malignancy justified? Ann Surg 2004 May;239(5):722-30.

24. de BT, Roche A, Elias D, Lasser P, Lagrange C, Bousson V. Preoperative portal vein embolization for extension of hepatectomy indications. Hepatology 1996 Dec;24(6):1386-91.

25. Adam R, Delvart V, Pascal G, et al. Rescue surgery for unresectable colorectal liver metastases downstaged by chemotherapy: a model to predict long-term survival Ann Surg 2004 0ct;240(4):644-57.

26. Kopetz S, Vauthey JN. Perioperative chemotherapy for resectable hepatic metastases. Lancet 2008 Mar 22;371(9617):963-5.

27. Belghiti J. [Synchronous and resectable hepatic metastases of colorectal cancer: should there be a minimum delay before hepatic resection?]. Ann Chir 1990;44(6):427-9.

28. Capussotti L, Muratore A, Ferrero A, Anselmetti GC, Corgnier A, Regge D. Extension of right portal vein embolization to segment IV portal branches. Arch Surg 2005 Nov; 140(11):1100-3.

29. Kubota K, Makuuchi M, Kusaka K, Kobayashi T, Miki K, Hasegawa K, Harihara Y, Takayama T. Measurement of liver volume and hepatic functional reserve as a guide to decision-making in resectional surgery for hepatic tumors. Hepatology 1997 Nov;26(5):1176-81.

30. Azoulay D, Castaing D, Smail A, Adam R, Cailliez V, Laurent A, Lemoine A, Bismuth $\mathrm{H}$. Resection of nonresectable liver metastases from colorectal cancer after percutaneous portal vein embolization. Ann Surg 2000 Apr;231(4):480-6.

31. Kianmanesh R, Farges 0 , Abdalla EK, Sauvanet A, Ruszniewski P, Belghiti J. Right portal vein ligation: a new planned two-step all-surgical approach for complete resection of primary gastrointestinal tumors with multiple bilateral liver metastases. J Am Coll Surg 2003 Jul;197(1):164-70.

32. Chun YS, Vauthey JN. Extending the frontiers of resectability in advanced colorectal cancer. Eur J Surg Oncol 2007 Dec;33 Suppl 2:S52-S58.

33. Popescu I, David L, Brasoveanu V, Boros M, Hrehoret D. Two-stage hepatectomy: an analysis of a single center's experience. Magy Seb 2006 Jun;59(3):184-9.

34. Kornprat $P$, Jarnagin WR, DeMatteo RP, Fong $Y$, Blumgart $L H$, D'Angelica $M$. Role of intraoperative thermoablation combined with resection in the treatment of hepatic metastasis from colorectal cancer. Arch Surg 2007 Nov;142(11):1087-92.

35. Popescu I, Alexandrescu S, Croitoru A, Boros M. Strategies to convert to resectability the initially unresectable colorectal liver metastases. Hepatogastroenterology 2009 May;56(91-92):739-44.

36. Popescu I, Alexandrescu ST. Surgical options for initially unresectable colorectal liver metastases. HPB Surg 2012;2012:454026.

37. Fusai $G$, Davidson BR. Strategies to increase the resectability of liver metastases from colorectal cancer. Dig Surg 2003;20(6):481-96

38. Jaeck $D$, Bachellier $P$, Nakano $H$, Oussoultzoglou $E$, Weber JC, Wolf $P$, Greget M. One or two-stage hepatectomy combined with portal vein embolization for initially nonresectable colorectal liver metastases. Am J Surg 2003 Mar; 185(3):221-9.

39. Elias D, Ouellet JF, de BT, Lasser P, Roche A. Preoperative selective portal vein embolization before hepatectomy for liver metastases: long-term results and impact on survival Surgery 2002 Mar;131(3):294-9.
40. Torres OJ, Fernandes ES, Oliveira CV, Lima CX, Waechter FL, MoraesJunior JM, Linhares MM, Pinto RD, Herman P, Machado MA. Associating liver partition and portal vein ligation for staged hepatectomy (ALPPS): the Brazilian experience Arq Bras Cir Dig 2013 Jan;26(1):40-3.

41. Skipenko OG, Chardarov NK, Bagmet NN, Bedzhanian AL, Polishchuk LO, Shatverian GA. [Associated liver partition and portal vein ligation for staged hepatectomy (ALPPS) - new opportunity in two-stage liver resection in patients with colorectal cancer metastases] Khirurgiia (Mosk) 2014;(9):23-9.

42. Zhang GQ, Zhang ZW, Lau WY, Chen XP. Associating liver partition and portal vein ligation for staged hepatectomy (ALPPS): a new strategy to increase resectability in liver surgery Int J Surg 2014;12(5):437-41.

43. Bertens KA, Hawel J, Lung K, Buac S, Pineda-Solis K, Hernandez-Alejandro R. ALPPS: challenging the concept of unresectability--a systematic review. Int J Surg 2015 Jan;13:280-7.

44. Jaeck D, Bachellier P, Nakano H, Oussoultzoglou E, Weber JC, Wolf P, Greget M. One or two-stage hepatectomy combined with portal vein embolization for initially nonresectable colorectal liver metastases Am J Surg 2003 Mar;185(3):221-9.

45. Adam R, Laurent A, Azoulay D, Castaing D, Bismuth H. Two-stage hepatectomy: A planned strategy to treat irresectable liver tumors. Ann Surg 2000 Dec;232(6):777-85.

46. Sugawara Y, Yamamoto J, Yamasaki S, Shimada K, Kosuge T, Makuuchi M. Estimating the prognosis of hepatic resection in patients with metastatic liver tumors from colorectal cancer with special concern for the timing of hepatectomy. Surgery 2001 Apr;129(4):408-13.

47. Shimada H, Tanaka K, Matsuo K, Togo S. Treatment for multiple bilobar liver metastases of colorectal cancer. Langenbecks Arch Surg 2006 Apr;391(2):130-42.

48. Alberts S, Poston G. OncoSurge: a strategy for long-term survival in metastatic colorectal cancer. Colorectal Dis 2003 Nov:5 Suppl 3:20-8.

49. Delaunoit T, Alberts SR, Sargent DJ, et al. Chemotherapy permits resection of metastatic colorectal cancer: experience from Intergroup N9741. Ann Oncol 2005 Mar; 16(3):425-9.

50. Hurwitz H, Fehrenbacher L, Novotny W, et al. Bevacizumab plus irinotecan, fluorouracil, and leucovorin for metastatic colorectal cancer. N Engl J Med 2004 Jun 3;350(23):2335-42.

51. Folprecht G, Grothey A, Alberts S, Raab HR, Kohne CH. Neoadjuvant treatment of unresectable colorectal liver metastases: correlation between tumour response and resection rates. Ann Oncol 2005 Aug; 16(8):1311-9.

52. Fernandez FG, Ritter J, Goodwin JW, Linehan DC, Hawkins WG, Strasberg SM. Effect of steatohepatitis associated with irinotecan or oxaliplatin pretreatment on resectability of hepatic colorectal metastases. J Am Coll Surg 2005 Jun;200(6):845-53.

53. Bilchik AJ, Poston G, Curley SA, Strasberg S, Saltz L, Adam R, Nordlinger $B$, Rougier $P$, Rosen LS. Neoadjuvant chemotherapy for metastatic colon cancer: a cautionary note. J Clin Oncol 2005 Dec 20;23(36):9073-8.

54. Rubbia-Brandt L, Audard V, Sartoretti P, et al. Severe hepatic sinusoidal obstruction associated with oxaliplatin-based chemotherapy in patients with metastatic colorectal cancer. Ann Oncol 2004 Mar;15(3):460-6

55. DeLeve LD, Shulman HM, McDonald GB. Toxic injury to hepatic sinusoids: sinusoidal obstruction syndrome (veno-occlusive disease) Semin Liver Dis 2002 Feb;22(1):27-42.

56. Adam R, Pascal G, Castaing D, Azoulay D, Delvart V, Paule B, Levi F, Bismuth $\mathrm{H}$. Tumor progression while on chemotherapy: a contraindication to liver resection for multiple colorectal metastases? Ann Surg 2004 Dec;240(6):1052-61.

57. Karoui M, Penna C, Amin-Hashem M, Mitry E, Benoist S, Franc B, Rougier $\mathrm{P}$, Nordlinger $\mathrm{B}$. Influence of preoperative chemotherapy on the risk of major hepatectomy for colorectal liver metastases. Ann Surg 2006 Jan;243(1):1-7

58. Adam R. [Resection of liver metastasis of colorectal origin following chemotherapy with irinotecan] Ann Chir 2004 Mar;129 Spec No 2:2-4.

59. Adam R, Lucidi V, Bismuth $\mathrm{H}$. Hepatic colorectal metastases: methods of improving resectability Surg Clin North Am 2004 Apr;84(2):659-71.

60. Adam R, Laurent A, Azoulay D, Castaing D, Bismuth H. Two-stage hepatectomy: A planned strategy to treat irresectable liver tumors Ann Surg 2000 Dec;232(6):777-85

61. Grundmann RT. Current state of surgical treatment of liver metastases from colorectal cancer. World J Gastrointest Surg 2011 Dec 27;3(12): 
183-96.

62. Soreide JA, Eiriksson K, Sandvik O, Viste A, Horn A, Johnsen G, Gronbech JE. [Surgical treatment of liver metastases from colorectal cancer]. Tidsskr Nor Laegeforen 2008 Jan 3;128(1):50-3.

63. Jaeck D, Bachellier P, Weber JC, Boudjema K, Mustun A, Paris F, Schaal JC, Wolf $P$. [Surgical strategy in the treatment of synchronous hepatic metastases of colorectal cancers. Analysis of a series of 59 operated on patients] Chirurgie 1999 Jun;124(3):258-63.

64. Reddy SK, Pawlik TM, Zorzi D, et al. Simultaneous resections of colorecta cancer and synchronous liver metastases: a multi-institutional analysis. Ann Surg Oncol 2007 Dec;14(12):3481-91.

65. Weber JC, Bachellier P, Oussoultzoglou E, Jaeck D. Simultaneous resection of colorectal primary tumour and synchronous liver metastases. $\mathrm{Br} J$ Surg 2003 Aug;90(8):956-62.

66. Popescu I, Alexandrescu ST. Metastatic colorectal cancer--what about the primary? Acta Chir lugosl 2012;59(2):47-55.

67. Adam R, de GA, Figueras J, et al. Managing synchronous liver metastases from colorectal cancer: A multidisciplinary international consensus. Cancer Treat Rev 2015 Nov;41(9):729-41.

68. Adam R, de GA, Figueras J, et al. The oncosurgery approach to managing liver metastases from colorectal cancer: a multidisciplinary international consensus. Oncologist 2012;17(10):1225-39.

69. Tsoulfas G, Pramateftakis MG. Management of rectal cancer and liver metastatic disease: which comes first? Int J Surg Oncol 2012 2012:196908.

70. Bradpiece HA, Benjamin IS, Halevy A, Blumgart LH. Major hepatic resection for colorectal liver metastases. Br J Surg 1987 Apr;74(4):324-6.

71. Thelen A, Jonas S, Benckert C, Schumacher G, Lopez-Hanninen E, Rudolph B, Neumann U, Neuhaus P. Repeat liver resection for recurrent liver metastases from colorectal cancer. Eur J Surg Oncol 2007 Apr; 33(3):324-8

72. Kingham TP, Scherer MA, Neese BW, Clements LW, Stefansic JD, Jarnagin WR. Image-guided liver surgery: intraoperative projection of computed tomography images utilizing tracked ultrasound. HPB (Oxford) 2012 Sep;14(9):594-603

73. Jarnagin WR, Gonen M, Fong Y, DeMatteo RP, Ben-Porat L, Little S, Corvera C, Weber S, Blumgart LH. Improvement in perioperative outcome after hepatic resection: analysis of 1,803 consecutive cases over the past decade. Ann Surg 2002 Oct;236(4):397-406.

74. Mentha G, Majno PE, Andres A, Rubbia-Brandt L, Morel P, Roth AD. Neoadjuvant chemotherapy and resection of advanced synchronous liver metastases before treatment of the colorectal primary $\mathrm{Br} J$ Surg 2006 Jul;93(7):872-8.

75. Verhoef C, van der Pool AE, Nuyttens JJ, Planting AS, Eggermont AM, de Wilt JH. The "liver-first approach" for patients with locally advanced rectal cancer and synchronous liver metastases. Dis Colon Rectum 2009 Jan;52(1):23-30.

76. Mayo SC, Pulitano C, Marques $\mathrm{H}$, et al. Surgical management of patients with synchronous colorectal liver metastasis: a multicenter international analysis. J Am Coll Surg 2013 Apr;216(4):707-16.

77. Fong Y, Fortner J, Sun RL, Brennan MF, Blumgart LH. Clinical score for predicting recurrence after hepatic resection for metastatic colorectal cancer: analysis of 1001 consecutive cases. Ann Surg 1999 Sep;230(3):309-18.

78. Fong Y, Fortner J, Sun RL, Brennan MF, Blumgart LH. Clinical score for predicting recurrence after hepatic resection for metastatic colorectal cancer: analysis of 1001 consecutive cases Ann Surg 1999 Sep;
230(3):309-18

79. Nordlinger B, Guiguet $M$, Vaillant JC, Balladur $\mathrm{P}$, Boudjema $\mathrm{K}$, Bachellier $\mathrm{P}$, Jaeck D. Surgical resection of colorectal carcinoma metastases to the liver. A prognostic scoring system to improve case selection, based on 1568 patients. Association Francaise de Chirurgie. Cancer 1996 Apr 1;77(7):1254-62.

80. Schlag $\mathrm{P}$, Hohenberger $\mathrm{P}$, Herfarth $\mathrm{C}$. Resection of liver metastases in colorectal cancer--competitive analysis of treatment results in synchronous versus metachronous metastases. Eur J Surg Oncol 1990 Aug; 16(4):360-5.

81. Lopez P, Marzano E, Piardi T, Pessaux P. Repeat hepatectomy for liver metastases from colorectal primary cancer: a review of the literature. J Visc Surg 2012 Apr;149(2):e97-e103.

82. Konopke R, Volk A, Gastmeier J, Ehehalt F, Distler M, Saeger HD, Kersting S. [Recurrent colorectal liver metastases: who benefits from a second hepatic resection?] Zentralbl Chir 2014 Apr;139(2):226-34.

83. Stone MD, Cady B, Jenkins RL, McDermott WV, Steele GD, Jr. Surgical therapy for recurrent liver metastases from colorectal cancer. Arch Surg 1990 Jun;125(6):718-21.

84. Takahashi M, Hasegawa K, Oba M, Aoki T, Sakamoto Y, Sugawara Y, Kokudo N. Repeat resection leads to long-term survival: analysis of 10-year follow-up of patients with colorectal liver metastases Am J Surg 2015 Nov;210(5):904-10.

85. Adam R, Bismuth H, Castaing D, Waechter F, Navarro F, Abascal A, Majno $P$, Engerran L. Repeat hepatectomy for colorectal liver metastases. Ann Surg 1997 Jan;225(1):51-60.

86. Muratore A, Polastri R, Bouzari H, Vergara V, Ferrero A, Capussotti L. Repeat hepatectomy for colorectal liver metastases: A worthwhile operation? J Surg Oncol 2001 Feb;76(2):127-32.

87. Sugarbaker PH. Repeat hepatectomy for colorectal metastases. J Hepatobiliary Pancreat Surg 1999;6(1):30-8.

88. Weber JC, Bachellier P, Jaeck D. Therapy options in colorectal liver metastases treatment. In: Editura Universitara "Carol Davila", editor. Surgery of Liver. 2004 ed. Bucharest: Popescu.l; 2004. p. 413-24.

89. Tocchi A, Mazzoni G, Liotta G, Lepre L, Costa G, Miccini M. [Recurrent liver metastases from colorectal cancer: their surgical treatment]. G Chir 1999 Jun;20(6-7):289-92.

90. Sa CA, Laurent C, Rault A, Couderc P, Rullier E, Saric J. A second liver resection due to recurrent colorectal liver metastases. Arch Surg 2007 Dec;142(12):1144-9.

91. Elias D, Ouellet JF, Bellon N, Pignon JP, Pocard M, Lasser P. Extrahepatic disease does not contraindicate hepatectomy for colorectal liver metastases. Br J Surg 2003 May;90(5):567-74.

92. Carpizo DR, Are C, Jarnagin W, Dematteo R, Fong Y, Gonen M, Blumgart L, D'Angelica M. Liver resection for metastatic colorectal cancer in patients with concurrent extrahepatic disease: results in 127 patients treated at a single center. Ann Surg Oncol 2009 Aug;16(8):2138-46.

93. de Haas RJ, Wicherts DA, Adam R. Resection of colorectal liver metastases with extrahepatic disease. Dig Surg 2008;25(6):461-6.

94. Elias D, Liberale G, Vernerey D, Pocard M, Ducreux M, Boige V, Malka D, Pignon JP, Lasser P. Hepatic and extrahepatic colorectal metastases: when resectable, their localization does not matter, but their total number has a prognostic effect Ann Surg Oncol 2005 Nov;12(11):900-9.

95. Adam R, de Haas RJ, Wicherts DA, Vibert E, Salloum C, Azoulay D, Castaing D. Concomitant extrahepatic disease in patients with colorectal liver metastases: when is there a place for surgery? Ann Surg 2011 Feb;253(2):349-59. 